\title{
Pure keratin membrane and fibers from chicken feather
}

\author{
Bomou Ma ${ }^{\text {a }}$, Xue Qiao ${ }^{\text {a }}$, Xiuliang Hou ${ }^{\text {a }}$, Yiqi Yang *bc \\ a: Key Laboratory of Eco-Textiles, Ministry of Education,
}

College of textile and clothing, Jiangnan University, Wuxi, Jiangsu, 214122, China

b: Department of Textiles, Merchandising \& Fashion Design, 234, HECO Building,

University of Nebraska-Lincoln, Lincoln, NE, 68583-0802, United States

c: Department of Biological Systems Engineering, 234, HECO Building, University

of Nebraska-Lincoln, Lincoln, NE, 68583-0802, United States

* corresponding author:

Phone: +086 5108591 2009; Fax: +086 51085912005 0640; Email:

mabomou@163.com

Phone: +001 402 472 5197; Fax: +001 402472 0640; Email: yyang2@unl.edu

ABSTRACT: In this research, keratin was extracted from the disposable chicken feather using L-cysteine as reducing agent. Then, it was re-dissolved in the sodium carbonate-sodium bicarbonate buffer, and the pure keratin membrane and fiber were fabricated by doctor-blade casting process and wet spinning method, respectively. Scanning electron microscopy (SEM), fourier transform infrared (FT-IR) spectroscopy, X-ray diffraction (XRD) and thermogravimetric analysis (TGA) were used to characterize the chemical and physical properties of resulting powder, membrane and fiber. Compared with the raw chicken feather, the regenerated keratin materials retain its chemical structure and thermal stability, their relative crystallinity is a little 
different depend on the shaping method, which leads to the difference in moisture regain. The mechanical results show that tensile strength of the keratin membrane researches $3.5 \mathrm{MPa}$, have potential application in biomedical fields. However, the keratin fiber presents low tenacity, i.e. $0.5 \mathrm{cN} / \mathrm{dtex}$, this problem should be solved in order to apply the new fiber in textile and material science.

KEYWORDS: keratin extraction; chicken feather; keratin fiber; keratin membrane

\section{INTRODUCTION}

Recent years, the development of protein materials has attracted the attention of many researchers. In this field, keratin is regarded as a promising candidate due to its excellent biocompatibility and biodegradability [1]. Keratin is one of the most abundant fibrous proteins that can be found in feather, wool, hair, finger nails, animal claws and horn [2], can be applied in tissue engineering [3,4], water purification [5,6], textile finishing [7], and composite materials [8-10]. Therefore, it is a significative work to explore the keratin-based materials. However, the keratin is a complex compounds, composed of 19 amino acids and linked together as ladder-like polypeptide chains by peptide bonds [11]. In addition, its molecular chains present tight packing of the $\alpha$-helix and $\beta$-sheet structure. All this leads keratin difficult to be extracted and dissolved in normal organic solvent. Nonetheless, methods for acid and alkaline hydrolysis, oxidation and reduction have been reported in the published literatures [11-13]. Reduction method is generally used at present because the keratin molecular weight extracted by other method is low for the polymer processing. For 
instance, Aluigi and Fortunati extracted the keratin from Merino wool by sulphitolysis using urea/meta-bisulphite/sodium dodecyl sulphate (SDS) as the solvent under $\mathrm{pH}$ 6.5 , respectively $[14,15]$. Xu extracted the wool keratin using urea/cysteine/SDS as the solvent under $\mathrm{pH} 10.5$ as well [16]. Besides, ionic liquids are proposed as a green solvent to extract the keratin due to its negligible vapor pressure and powerful dissolving property for polysaccharide, which attracts many researchers commit to this field [17-19]. In 2005, Xie first reported that ionic liquid 1-butyl-3-methylimidazolium chloride can be used to extract the keratin from wool fibers directly [20]. After that, some composite materials based on natural wool were prepared, for instance wool/cellulose blend and wool/cellulose acetate blend [21,22]. Up to now, some other ionic liquids, i.e. 1-allyl-3-methylimidazolium chloride, 1-allyl-3-methylimidazolium dicyanamide, choline thioglycolate and $\mathrm{N}, \mathrm{N}$-dimethylethanolammonium formate, are also proposed to directly extract the keratin from wool and poultry feather [23-25].

In our daily life, chicken feathers are a waste byproduct of poultry industry with more than $4 * 10^{6}$ ton per year in the worldwide [8], and consists of $91 \%$ keratin macromolecules with an average molecular weight of $10 \mathrm{kDa}[26,27]$. In general, some of them are pretreated and used as animal feed with low nutritional value [28], the rest are disposed through landfills, which will cause environmental problems. Therefore, reduction method and ionic liquid have been reported to extract feather keratin and prepare keratin-based composite materials [2,26,27,29]. Even so, there are still few literatures concerning the preparation and properties of pure protein materials 
based on keratin.

The aim of this study is to explore the feasibility of transforming feather waste into useful protein materials. In the current work, keratin was extracted from chicken feather by breaking the disulfide bond networks using L-cysteine as reducing agent, the fresh keratin was dried and pulverized to obtain the keratin powder with sub-micron. Besides, the fresh keratin was re-dissolved and formed a homogeneous solution, SDS was introduced to control the conformation of macromolecular chains to meet the requirement of membranes and fibers fabrication. Finally, the pure keratin membrane and fiber were prepared by doctor-blade casting process and wet spinning method, respectively. A combination of analytical techniques including Scanning electronic microscopy (SEM), Fourier transform infrared spectroscopy (FT-IR), Wide angle x-ray diffraction (WAXD), Thermo gravimetric analyzer (TGA) and moisture regain were used to characterize the chemical and structure properties of raw feather, keratin powder, membranes and fibers, the mechanical properties of keratin membranes and fibers were investigated as well. All the results show that it is feasible to process the keratin extracted from waste chicken feather into useful membranes and fibers, which presents huge potential application in membrane technology and functional textile industry.

\section{MATERIALS AND METHODS}

\subsection{Materials}

The white chicken feather was obtained from American Featherfiber Corporation (Nixa, MO). Urea ( $\geq 99 \%$, AR), L-cysteine ( $\geq 98.5 \%$, BR), SDS (CP), $\mathrm{Na}_{2} \mathrm{CO}_{3}$, 
$\mathrm{NaHCO}_{3}$ and glycerol were purchased from Sinopharm Chemical Reagent Co. Ltd. (Shanghai, China), and used as-received.

\subsection{Keratin Extraction}

Based on previous study in our group [30], the optimal condition were used to extract the keratin. A certain weight of cleaned chicken feather were put in mixed solution containing 8mol/L urea and L-cysteine, adjusted to $\mathrm{pH} 10.5$ using $50 \%$ $\mathrm{NaOH}$ solution and treated under mechanical stirring for $12 \mathrm{~h}$ at $70^{\circ} \mathrm{C}$. The weight ratio of $8 \mathrm{M}$ urea solution to chicken feather was 17:1, which just completely immersed the feather in urea solution. The concentration of L-cysteine was $10 \%$ based on the weight of chicken feather. After treatment, the feather dispersion was centrifuged at $10000 \mathrm{rmp}$ for $20 \mathrm{~min}$ to obtain the supernatant, adjusted to $\mathrm{pH} 4$ using hydrochloric acid and sodium sulfate to precipitate the dissolved keratin. The collected participate was washed three times with DI water, filtered and removed the surface water with napkin. Finally, its water content was about $70 \%$, and named as fresh keratin. It was freeze dried and pulverized to obtain the keratin powder, the yield is about $60 \%$.

\subsection{Fabrication of keratin membranes and fibers}

0.1 M sodium carbonate-sodium bicarbonate buffer with $\mathrm{pH} 9.5$ was added into the fresh keratin, and adjusted the keratin concentration to $15 \% .10 \%$ SDS based on the dried keratin was introduced to control the conformation of macromolecular chains. Then, The $15 \%$ keratin mixture was aged for $24 \mathrm{~h}$ at room temperature and heated at $90^{\circ} \mathrm{C}$ for $1 \mathrm{~h}$ to obtain the homogeneous solution. At this time, $10 \%$ glycerol 
based on the dried keratin was added immediately, and the solution was casted onto a PTFE mould and evaporated in $60^{\circ} \mathrm{C}$ oven to obtain the keratin membrane. This membrane was immersed in coagulation bath $\left(\mathrm{V}_{10 \% \text { ethanol }}: \mathrm{V}_{10 \% \text { acetic acid }}=1: 1\right)$ and $10 \%$ glycerol solution successively, removed the surface water and conditioned under $25^{\circ} \mathrm{C}$ and $65 \%$ relative humidity.

The above-mentioned homogeneous solution can also be used as the spinning drops to fabricate the keratin fibers by wet method. The solution was extruded through a spinneret with 30 holes $60 \mu \mathrm{m}$ diameter under the $0.2 \mathrm{MPa}$ and $60^{\circ} \mathrm{C}$, then immersed directly in the $25^{\circ} \mathrm{C}$ coagulation bath composed of $10 \%$ ethanol and $10 \%$ acetic acid, passed through the drawing bath and washing bath successively, the regenerated keratin fibers were collected. They were soaked in the $10 \%$ glycerol solution as post treatment, squeezed the extra water and conditioned under $25^{\circ} \mathrm{C}$ and $65 \%$ relative humidity.

\subsection{Measurements}

SEM: surface morphology of the freeze dried keratin was observed by Hitachi S4800, keratin membrane and fiber were observed by HITACHI SU1510. In preparation the samples, freeze dried keratin was adhered onto an aluminium stub with conductive tapes and then coated with a thin layer of gold. The membrane and fiber samples were washed with DI water for three times to remove the glycerol, and adhered onto the stub for surface observation. For the cross section observation, the membrane and fiber were fractured under liquid nitrogen.

FT-IR: the chemical structures of raw chicken feather, keratin powder, membrane 
and fiber were obtained using a Thermo Fisher Nicolet iS10 FT-IR with attenuated total reflection (ATR) accessory. The FT-IR was performed in the wave number range of 500 to $4000 \mathrm{~cm}^{-1}$ with transmission mode.

WAXD: the crystallinity differences of all the samples were obtained from Rigaku D/Max-2250 WAXD with Cu radiation operated at 40KV and 200mA. The $2 \alpha$ Bragg angles were scanned in the range of $5-60^{\circ}$ using a $0.05^{\circ}$ step and $10^{\circ} / \mathrm{min}$ scan step. For the fiber sample, it was cut into short pieces for testing. Crystallinity index was employed to characterize the relative crystallinity degree according to the reference in this study [31].

$C_{r} \bullet I_{.}=\left[\left(I_{9^{\circ}}-I_{14^{\circ}}\right) / I_{9^{\circ}}\right] \times 100 \%$

where $C_{r} \bullet I$. is the crystallinity index; $I_{9^{\circ}}$ is the maximum intensity of crystal lattice diffraction at about $9^{\circ} ; \mathrm{I}_{14^{\circ}}$ is the minimum intensity at about $14^{\circ}$. Generally, the high $\mathrm{C}_{\mathrm{r}} \bullet \mathrm{I}$ value indicates the more crystallinity of materials.

TGA: thermal stability of raw feather and regenerated powder, membrane, fiber were investigated by Mettler-Toledo 1100SF TGA in a flowing nitrogen atmosphere between 50 and $600^{\circ} \mathrm{C}$ at a heating rate of $10^{\circ} \mathrm{C} / \mathrm{min}$.

Moisture regain trials: all the samples were washed with DI water and dried at $105^{\circ} \mathrm{C}$ for $1 \mathrm{~h}$, then weighed it on Mettler XS105. Their weights were recorded at certain interval time until constant weight under equilibrium condition, i.e. $25^{\circ} \mathrm{C}$ and $65 \%$ relative humidity. The collected data were used for further calculations and analysis.

Mechanical testing: tensile strength of the regenerated keratin membrane was 
measured with WDW3020 materials testing system (Changchun Kexin Instrument Limited Corporation) with a crosshead speed of $10 \mathrm{~mm} / \mathrm{min}$. In preparation the samples, the fabricated membrane was cut into rectangular shape with $80 \mathrm{~mm} \times 10 \mathrm{~mm}$. Tensile strength of the keratin fibers was performed on XQ-1 fiber tensile tester (Shanghai New Fiber Instrument Limited Corporation) with an extension speed of 10 $\mathrm{mm} / \mathrm{min}$ under room temperature. Before the testing, both membrane and fiber were allowed to equilibrate under $25^{\circ} \mathrm{C}$ and $65 \%$ relative humidity for 2 days.

\section{RESULTS AND DISCUSSION}

\subsection{Reduction and precipitation of the keratin}

Keratin are stabilized by disulphide crosslinkages of cystine, it must be split apart in order to extract the keratin. Cysteine is a kind of sulfhydryl compound with reducibility, they can break up the disulfide bond under $\mathrm{pH} 9-10$, which is the $\mathrm{pK}$ value for thiol group, as shown in Fig. 1 equation (1) and (2). The reduced keratin can be dissolved in the concentrated urea solution, which is the protein swelling medium. Finally, the supernatant was obtained by centrifugation. The dissolved keratin was regenerated when the supernatant was adjusted to its isoelectric-point about $\mathrm{pH} 4$ using hydrochloric acid and sodium sulfate, as shown in Fig. 2 a, its microtopography is shown in Fig. 2 b. It can be seen that the regenerated keratin presents nano-scale microsphere with the diameter of $200-500 \mathrm{~nm}$, this is accordance with the results of wool keratin and feather keratin in publications $[11,26,29]$. These pulverized keratins have huge potential application in surface modification, water treatment and feed ingredient $[28,32,33]$. However, in our experiment, the dried keratin powder cannot 
be re-dissolved in $0.1 \mathrm{M}$ sodium carbonate-sodium bicarbonate buffer to prepare the keratin membrane and fiber. That is because the reduced keratin $\mathrm{K}_{-} \mathrm{CH}_{2}-\mathrm{SH}$ is unstable and easily to be oxidized and form the disulfide bond again, as shown in Fig. 1 equation (3). Therefore, the fresh keratin should be stored in sealed to prepare the solution.

3.2. Surface morphology of the keratin membrane and fiber

The fresh keratin was dissolved in the sodium carbonate buffer and formed $15 \%$ solution. Because the solution is easily to be oxidized in air, the carbonyl compounds must be introduced to the cysteine residues of keratin [29]. Sodium dodecyl sulfate (SDS) is a typical negatively charged surfactant, this negative charge is greater than the charge of keratin, so the charge of keratin can be ignored. Moreover, the electrostatic repulsion created by the binding of SDS causes keratin macromolecular chains to unfold. Therefore, SDS was introduced here to protect the reduced keratin and prevent the aggregation as it forms complex compound with keratin [26,29]. The homogeneous solution was applied to fabricate the membrane and fiber. In general, the prepared keratin membrane and fiber are brittle. Therefore, glycerol was used as plasticizer in the matrix to improve its flexibility according to the literatures $[34,35]$.

Fig. 3 shows the microstructure of prepared membrane and fiber. It can be seen that the surface and cross section of the membrane is uniform with a roughness on the micro level, which is different from the chitosan membrane prepared by the same method [36]. That is because the introduction of SDS uniformed the complex structure of keratin macromolecular chains, and makes them a cylinder shape with 
large amount of negative charge, which leads to the strong electrostatic repulsion. When the keratin solution was dried, its macromolecular chains can't close to each other infinitely due to the strong electrostatic repulsion. In regeneration process, the SDS was removed and left the space to form the porous microstructure in membrane matrix, as shown in Fig. 4. From the SEM images of keratin fibers, it can be seen that they present round cross section and possess many micro pores, which is mainly caused by the severe double diffusion between keratin filament and coagulation bath. There is no doubt that it can be adjusted by changing the composition of coagulation. And the micro pores will have great effects on fiber mechanical property, this will be discussed later.

Mechanical property is a very important characterization for any materials, which directly affect the application. Fig. 5 presents the mechanical results of pure keratin membrane and fiber. It shows that tensile strength of the keratin membrane researches $3.5 \mathrm{MPa}$ with break elongation of $127 \%$, that of keratin fiber is $0.5 \mathrm{cN} / \mathrm{dtex}$ with break elongation of $28 \%$. For the practical use, the membrane doesn't need to reinforce with other polymer. However, the strength of keratin fiber is inferior due to many micropores embedded in it. Therefore, it is necessary to adjust the coagulation bath and improve the strength of these fibers in order to apply it in textile and materials science, this will be the next work for us. Besides, both break elongation is high, although there are some literatures reported that the pure keratin was fragile $[14,29]$. This is mainly ascribed to the introduction of glycerol to plasticize the keratin macromolecular chains [10,29]. 


\subsection{Characterization of the regenerated keratin materials}

\subsubsection{FT-IR analysis}

In order to understand the chemical structure of raw chicken feather, regenerated keratin powder, membrane and fiber, FT-IR measurement was used, and the results are shown in Fig. 6. Compare the profiles of four samples, their characteristic peaks are similar. This confirms the keratin content in raw feather is very high so that its characteristic peaks are accordance with the extracted pure keratin. On the other hand, the processing methods have little effect on the chemical structure of protein. Whether it is keratin powder or membrane or fiber, they all show characteristic transmission bands ascribed predominantly to the peptide bonds (-CONH) and these have been labeled as Amide A, Amide I, Amide II and Amide III $[1,23]$. The transmission band at $3281 \mathrm{~cm}^{-1}$ is attributed to the stretching vibrations of $\mathrm{O}-\mathrm{H}$ and $\mathrm{N}-\mathrm{H}$ (Amide A), the band at $2923 \mathrm{~cm}^{-1}$ is attributed to the symmetrical $\mathrm{CH}_{3}$ stretching vibration [37], while the strong transmission band at $1630 \mathrm{~cm}^{-1}$ is related to the $\mathrm{C}=\mathrm{O}$ stretching (Amide I). The Amide II with the band at $1521 \mathrm{~cm}^{-1}$ is derived from $\mathrm{N}-\mathrm{H}$ bending and $\mathrm{C}-\mathrm{H}$ stretching. A weak band at $1233 \mathrm{~cm}^{-1}$ is assigned to the Amide III, which is due to the combination of C-N stretching and $\mathrm{N}-\mathrm{H}$ in plane bending as well as some contribution from $\mathrm{C}-\mathrm{C}$ stretching and $\mathrm{C}=\mathrm{O}$ bending vibration $[2,11]$. The Amide I-III bands give critical information on the protein conformation and backbone structure. According to the literature data, the peaks at $3293 \mathrm{~cm}^{-1}$ (Amide A) indicates $\alpha$-helix structure, the range of $1539-1515 \mathrm{~cm}^{-1}$ (Amide II) is related to the $\beta$-sheet structure, the split peaks at $1666 \mathrm{~cm}^{-1}$ and $1655 \mathrm{~cm}^{-1}$ (Amide I) is the combination of $\alpha$-helix and $\beta$-sheet 
[38,39]. Therefore, all the four samples possess two micro-structures of $\alpha$-helix and $\beta$-sheet. The quantitative analysis of the content of $\alpha$-helix and $\beta$-sheet in four samples can be found in Fig. 7, and the results is concluded in Table 1. It shows that the content of $\alpha$-helix is decreased after the dissolution and regeneration process, this is accrodance with the results of publication [24]. The content of $\beta$-sheet in chicken feather is higher than that of $\alpha$ helix, this may be due to the used chicken feather is composed of more quill than feather fibers. The reference reported that quill fraction is composed of more $\beta$-sheet than $\alpha$ helix while the feather fiber has a higher percentage of $\alpha$ helix compared to $\beta$-sheet [40]. Besides, the percentage of $\alpha$ helix, $\beta$-sheet+random coil and turns in keratin powder, keratin membrane and keratin fibers is a little different, it seems that stretching is beneficial to the formation of $\alpha$ helix.

\subsubsection{WAXD analysis}

X-ray diffraction (XRD) is an important technique to determine the crystal of samples. Fig. 8 shows the XRD patterns of raw chicken feather and regenerated keratin materials, their relative crystallinity is characterized by $\mathrm{C}_{\mathrm{r}} \bullet \mathrm{I}$. Compare the profiles of four samples, they all present broad peaks at about $19^{\circ}$, the peak intensity of chicken feather is lower than that of regenerated keratin materials. According to the reference, the peak at $17.8^{\circ}$ corresponds to the diffraction pattern of $\alpha$-helix, whereas the peak at $19^{\circ}$ is typical peak of $\beta$-sheet structure [2]. However, the two peaks usually are not to be clearly assigned due to the overlapping signals, this leads to the broad single peaks at $19^{\circ}$. In this viewpoint, all the four samples present two structures of $\alpha$-helix and $\beta$-sheet, this is consistent with the results from FT-IR. The 
peak intensity indicates the content of crystal structure, therefore, the regenerated keratin materials possess more content of $\beta$-sheet compared with the raw chicken feather. The peak at about $9^{\circ}$ is corresponds to the $\alpha$-helix configuration $[5,41]$, the three samples present an obvious peak at this position besides the keratin membrane, and the peak intensity of chicken feather is stronger than that of the other samples. This suggests a more content of $\alpha$-helix structure in chicken feather. Based on the above analysis, it indicates that both chicken feather and regenerated keratin materials possess two kinds of crystal structure of $\alpha$-helix and $\beta$-sheet, however, the regenerated keratin materials present greater content of $\beta$-sheet than raw chicken feather.

It is well known that keratin is a semi-crystalline natural macromolecular, this has been confirmed by its XRD profiles. However, their relative crystallinity is a little difference for the four keratin samples. Specifically speaking, the $C_{r} \bullet I$. of chicken feather is 0.43 , the $\mathrm{C}_{\mathrm{r}} \bullet \mathrm{I}$. of regenerated keratin, i.e. powder, membrane and fibers, is lower than that of raw feather. The keratin extraction is a process to destroy the original crystal domain in dissolution and rebuild a new one in regeneration. However, it is not all the destroyed crystal can be rebuilt in the regeneration process, this depends on the shaping method, and leads to the crystallinity difference. The high $\mathrm{C}_{\mathrm{r}} \bullet$ I. of keratin fiber $(0.17)$ is mainly ascribed to the draw ratio during spinning process.

\subsubsection{TGA analysis}

Thermal stability of the raw feather and regenerated keratin materials was conducted by TGA. As shown in Fig. 9, all the profiles present a similar pattern with two stages of decomposition, indicates that thermal stability of original chicken 
feather has been retained. Specifically speaking, there are 5-8\% weight loss before $100^{\circ} \mathrm{C}$, this is ascribed to the evaporation of incorporated water including 'free water' and 'bounded water'. The four samples are stable until $200^{\circ} \mathrm{C}$, and occurs a sharp weight loss from $200^{\circ} \mathrm{C}$ to $400^{\circ} \mathrm{C}$ with a decrease range reaches up to $70 \%$. This is associated with the denaturation of helix structure and the destruction of chain linkages, peptide bridges and the skeletal degradation [39]. At the same time, several chemical reactions occur in this range where the keratin are decomposed to lighter products and volatile compounds such as $\mathrm{CO}_{2}, \mathrm{H}_{2} \mathrm{~S}, \mathrm{H}_{2} \mathrm{O}$ and $\mathrm{HCN}$ [42]. From the DTG profiles, all the four samples reach a maximum decomposition rate at about $335 \pm 5^{\circ} \mathrm{C}$, there are negligible difference between them. This indicates the extraction process and shaping method have little effect on the thermal stability of keratin.

\subsubsection{Moisture regain results}

Moisture regain is an important character, which has great effect on the comfortability of textile materials. Fig. 10 shows the moisture regain curves of raw chicken feather, regenerated keratin powder, membrane and fiber under certain condition for $48 \mathrm{~h}$. It shows that all the curves present a quick increase first and then tends to be stable. Specifically speaking, moisture regain of the chicken feather is about $7.7 \%$, which is similar with keratin fibers (7.5\%). This is mainly ascribed to their similar microstructure [39]. However, the values of keratin powder and membrane can research up to $12.1 \%$ and $14.7 \%$, respectively. This is far higher than raw feather and regenerated fibers. It is well known that the incorporated water in materials includes 'free water' and 'bound water', they are easier to penetrate the 
amorphous domain than crystal area. Therefore, the high moisture regains of keratin powder and membrane is closely associated with its low crystallinity (show in Fig. 8). For the powder, the high water retention contributes to its potential application in moisturizing and sun protection creams [26], similarly, the appropriate moisture regain for textile fibers endows it hygroscopicity and sweat releasing properties. In addition, the moisture absorption rate of keratin membrane is lower than that of the other three samples at the beginning of $2 \mathrm{~h}$. This is related to its low specific surface, which leads to few exposure of the hydrophilic sites in keratin macromolecular chains and affect the moisture absorption rate furthermore. In this way, the moisture regain is not only associated with crystallinity, but also the specific surface of materials.

\section{CONCLUSIONS}

In the present study, we confirmed that it is feasible to transform the disposable chicken feather into useful powder with sub-micron, membrane and fiber. The extracted fresh keratin is very easily to be oxidized in the air, should be stored in sealed. During the extraction and re-shaping process, the chemical structure and thermal stability of raw chicken feather are retained in the keratin powder, membrane and fiber. However, their relative crystallinity has a little difference. Specifically speaking, the $\mathrm{C}_{\mathrm{r}} \cdot \mathrm{I}$. of keratin fiber researches 0.17 due to the draw ratio during spinning process, that of keratin membrane is too low, i.e. 0.03. The different crystallinity leads to the difference in moisture regain, which is associated with crystallinity and specific surface of materials. For instance, the moisture regain of keratin fiber and membrane is $7.5 \%$ and $14.7 \%$, respectively. Most important, the 
mechanical property of pure keratin membrane is $3.5 \mathrm{MPa}$, doesn't need to blend with the other polymers, has potential application in tissue engineering, drug delivery, and so forth. However, the tensile strength of pure keratin fiber is $0.5 \mathrm{cN} / \mathrm{dtex}$ with break elongation of $28 \%$. This value is inferior for the practical use, more work should be done to solve the problem.

\section{ACKNOWLEDGMENTS}

The authors greatly acknowledge the financial support from the Scientific Support Program of Jiangsu Province (No. BY2013015-17) and the Fundamental Research Funds for the Central Universities (No. JUSRP51505 and No. JUSRP11502). Yang also thanks USDA (National Agriculture and Food Initiative, Hatch Act, Multistate Research Project S-1054 (NEB37-037)), and Agricultural Research Division at the University of Nebraska-Lincoln for their support of his part of the work.

\section{REFERENCES}

[1] A. Aluigi, M. Zoccola, C. Vineis, C. Tonin, F. Ferrero, M. Canetti, Int. J. Biol. Macromol., 41 (2007) 266-273.

[2] A. Idris, R. Vijayaraghavan, U.A. Rana, D. Fredericks, A.F. Patti, D.R. MacFarlane, Green Chem., 15 (2013) 525-534.

[3] H. Xu, S. Cai, L. Xu, Y. Yang, Langmuir, 30 (2014) 8461-8470.

[4] J. Li, Y. Li, L. Li, A.F.T. Mak, F. Ko, L. Qin, Compos. Part B-Eng., 40 (2009) 664-667. 
[5] M.A. Khosa, A. Ullah, J. Hazard. Mater., 278 (2014) 360-371.

[6] P. Kar, M. Misra, J. Chem. Technol. Biot., 79 (2004) 1313-1319.

[7] D. Yu, J.Y. Cai, J.S. Church, L. Wang, Int. J. Biol. Macromol., 78 (2015) 32-38.

[8] A.E. Jiménez-Cervantes, C. Velasco-Santos, A.L. Martínez-Hernández, J.L. Rivera-Armenta, A.M. Mendoza-Martínez, V.M. Castaño, J. Compos. Mater., 49 (2015) 275-283.

[9] C.K. Hong, R.P. Wool, J. Appl. Polym. Sci., 95 (2005) 1524-1538.

[10] J. Choi, G. Panthi, Y. Liu, J. Kim, S.H. Chae, C. Lee, M. Park, H.Y. Kim, Polymer, 58 (2015) 146-152.

[11] J. Zhang, Y. Li, J. Li, Z. Zhao, X. Liu, Z. Li, Y. Han, J. Hu, A. Chen, Powder Technol., 246 (2013) 356-362.

[12] P. Hill, H. Brantley, M. Van Dyke, Biomaterials, 31 (2010) 585-593.

[13] J. Fan, W.D. Yu, Fiber. Polym., 13 (2012) 1044-1049.

[14] A. Aluigi, C. Vineis, A. Varesano, G. Mazzuchetti, F. Ferrero, C. Tonin, Eur. Polym. J., 44 (2008) 2465-2475.

[15] E. Fortunati, A. Aluigi, I. Armentano, F. Morena, C. Emiliani, S. Martino, C. Santulli, L. Torre, J.M. Kenny, D. Puglia, Mat. Sci. Eng. C-Mater., 47 (2015) 394-406.

[16] H. Xu, Z. Ma, Y. Yang, J. Mater. Sci., 49 (2014) 7513-7521.

[17] J. Chen, V. Kylie, X. Wang, B. Nolene, Materials, 7 (2014) 6158-6168.

[18] R. Li, D. Wang, J. Appl. Polym. Sci., 127 (2013) 2648-2653.

[19] A. Ghosh, S. Clerens, S. Deb-Choudhury, J.M. Dyer, Polym. Degrad. Stabil., 108 
(2014) 108-115.

[20] H. Xie, S. Li, S. Zhang, Green Chem., 7 (2005) 606.

[21] N. Hameed, Q. Guo, Cellulose, 17 (2010) 803-813.

[22] N. Hameed, Q. Guo, Carbohyd. Polym., 78 (2009) 999-1004.

[23] A. Idris, R. Vijayaraghavan, U.A. Rana, A.F. Patti, D.R. MacFarlane, Green Chem., 16 (2014) 2857.

[24] A. Idris, R. Vijayaraghavan, A.F. Patti, D.R. MacFarlane, ACS Sustain. Chem. Eng., 2 (2014) 1888-1894.

[25] Y. Ji, J. Chen, J. Lv, Z. Li, L. Xing, S. Ding, Sep. Purif. Technol., 132 (2014) $577-583$.

[26] Z. Pedram Rad, H. Tavanai, A.R. Moradi, J. Aerosol Sci., 51 (2012) 49-56.

[27] Y.X. Wang, X.J. Cao, Process Biochem., 47 (2012) 896-899.

[28] A. Bertsch, N. Coello, Bioresource Technol., 96 (2005) 1703-1708.

[29] X.C. Yin, F.Y. Li, Y.F. He, Y. Wang, R.M. Wang, Biomater. Sci., 1 (2013) $528-536$.

[30] H. Xu, Y. Yang, ACS Sustain. Chem. Eng., 2 (2014) 1404-1410.

[31] J.J. Long, C.L. Cui, L. Wang, H.M. Xu, Z.J. Yu, X.P. Bi, J. Clean. Prod., 43 (2013) 52-58.

[32] D. Touaibia, B. Benayada, Desalination, 186 (2005) 75-80.

[33] P. Gao, K. Li, Z. Liu, B. Liu, C. Ma, G. Xue, M. Zhou, Water Air Soil Poll., 225 (2014) 1-13.

[34] A. Ullah, T. Vasanthan, D. Bressler, A.L. Elias, J. Wu, Biomacromolecules, 12 
(2011) 3826-3832.

[35] C. Mangavel, J. Barbot, J. Guéguen, Y. Popineau, J. Agr. Food Chem., 51 (2003) $1447-1452$.

[36] B. Ma, X. Li, A. Qin, C. He, Carbohyd. Polym., 91 (2013) 477-482.

[37] H.G.M. Edwards, D.E. Hunt, M.G. Sibley, Spectrochim. Acta A, 54 (1998) 745-757.

[38] E. Senoz, R.P. Wool, J. Appl. Polym. Sci., 118 (2010) 1752-1765.

[39] A.L. Martinez-Hernandez, C. Velasco-Santos, M.D. Icaza, V.M. Castano, Int. J. Environ. Pollut., 23 (2005) 162-178.

[40] A. Ullah, J. Wu, Macromol. Mater. Eng., 298 (2013) 153-162.

[41] A.J. Poole, J.S. Church, Int. J. Biol. Macromol., 73 (2015) 99-108.

[42] C. Popescu, P. Augustin, J. Therm. Anal. Calorim., 57 (1999) 509-515.

Figure Captions

Fig. 1. Schematic of keratin reduction (1 and 2) and oxidation (3)

Fig. 2. Precipitation of the dissolved keratin under isoelectric-point (a) and the microtopography of freeze dried keratin (b)

Fig. 3. Digital photographs and SEM images of the prepared keratin membrane and fiber

Fig. 4. Schematic of the SDS function and keratin membrane formation

Fig. 5. Mechanical properties of the fabricated pure keratin membrane and fiber

Fig. 6. FT-IR spectra of the raw chicken feather and regenerated keratin powder, 
membrane and fiber

Fig. 7. The deconvolution of FT-IR spectra in Amide I region of chicken feather, keratin powder, keratin membrane and keratin fibers

Fig. 8. Wide angle X-ray diffractograms of the raw chicken feather and three regenerated keratin samples

Fig. 9. TGA and corresponding DTG curves of the raw chicken feather and three regenerated keratin samples

Fig. 10. Water content vs. time curves of the raw chicken feather and three regenerated keratin samples

Table Caption

Table 1 The quantitative analysis of $\alpha$ helix and $\beta$-sheet+random coil of chicken feather, keratin powder, keratin membrane and keratin fibers, which were deduced after Fourier self-deconvolution and fitted using Peakfit software. 


\begin{tabular}{|c|c|c|c|}
\hline Materials & Wavenumber/cm & Assignment & \% Fraction \\
\hline \multirow{2}{*}{ Chicken } & 1625 & $\beta$-sheet+random coil & 53.6 \\
\hline Feather & 1654 & $\alpha$-helix & 32.2 \\
\hline \multirow{2}{*}{ Keratin } & 1678 & Turns & 14.2 \\
\hline Powder & 1631 & $\beta$-sheet+random coil & 62.9 \\
\hline \multirow{2}{*}{ Keratin } & 1656 & $\alpha$-helix & 15.5 \\
\hline Membrane & 1672 & Turns & 21.6 \\
\hline \multirow{2}{*}{} & 1625 & $\beta$-sheet+random coil & 58.5 \\
\hline \multirow{2}{*}{ Keratin Fibers } & 1650 & $\alpha$-helix & 20.0 \\
\hline & 1667 & Turns & 21.4 \\
\hline & 1626 & $\beta$-sheet+random coil & 52.5 \\
\hline
\end{tabular}


$\mathrm{K}-\mathrm{CH}_{2}-\mathrm{S}-\mathrm{S}-\mathrm{CH}_{2}-\mathrm{K}+\mathrm{RSH} \longrightarrow \mathrm{K}-\mathrm{CH}_{2}-\mathrm{S}-\mathrm{S}-\mathrm{R}+\mathrm{K}-\mathrm{CH}_{2}-\mathrm{SH}$ equation (1) (keratin) (reduction agents)

$\mathrm{K}-\mathrm{CH}_{2}-\mathrm{S}-\mathrm{S}-\mathrm{R}+\mathrm{RSH} \longrightarrow \mathrm{R}-\mathrm{S}-\mathrm{S}-\mathrm{R}+\mathrm{K}-\mathrm{CH}_{2}-\mathrm{SH}$ equation (2)

$\mathrm{K}-\mathrm{CH}_{2}-\mathrm{SH}+\mathrm{K}-\mathrm{CH}_{2}-\mathrm{SH} \stackrel{\text { oxidation }}{\longrightarrow} \mathrm{K}-\mathrm{CH}_{2}-\mathrm{S}-\mathrm{S}-\mathrm{CH}_{2}-\mathrm{K}$ equation (3) 
Keratin Materials

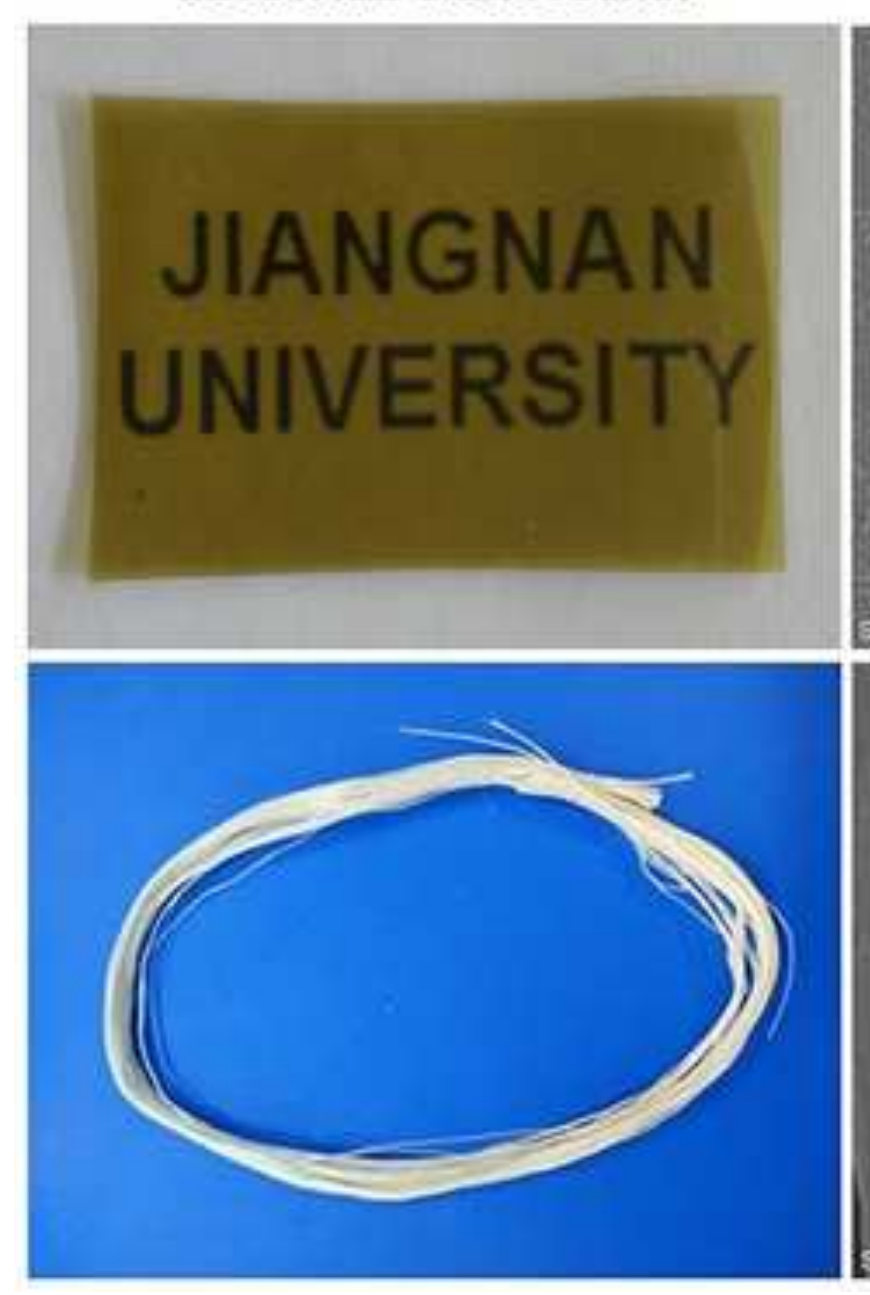

Surface

$300 \mathrm{n}$

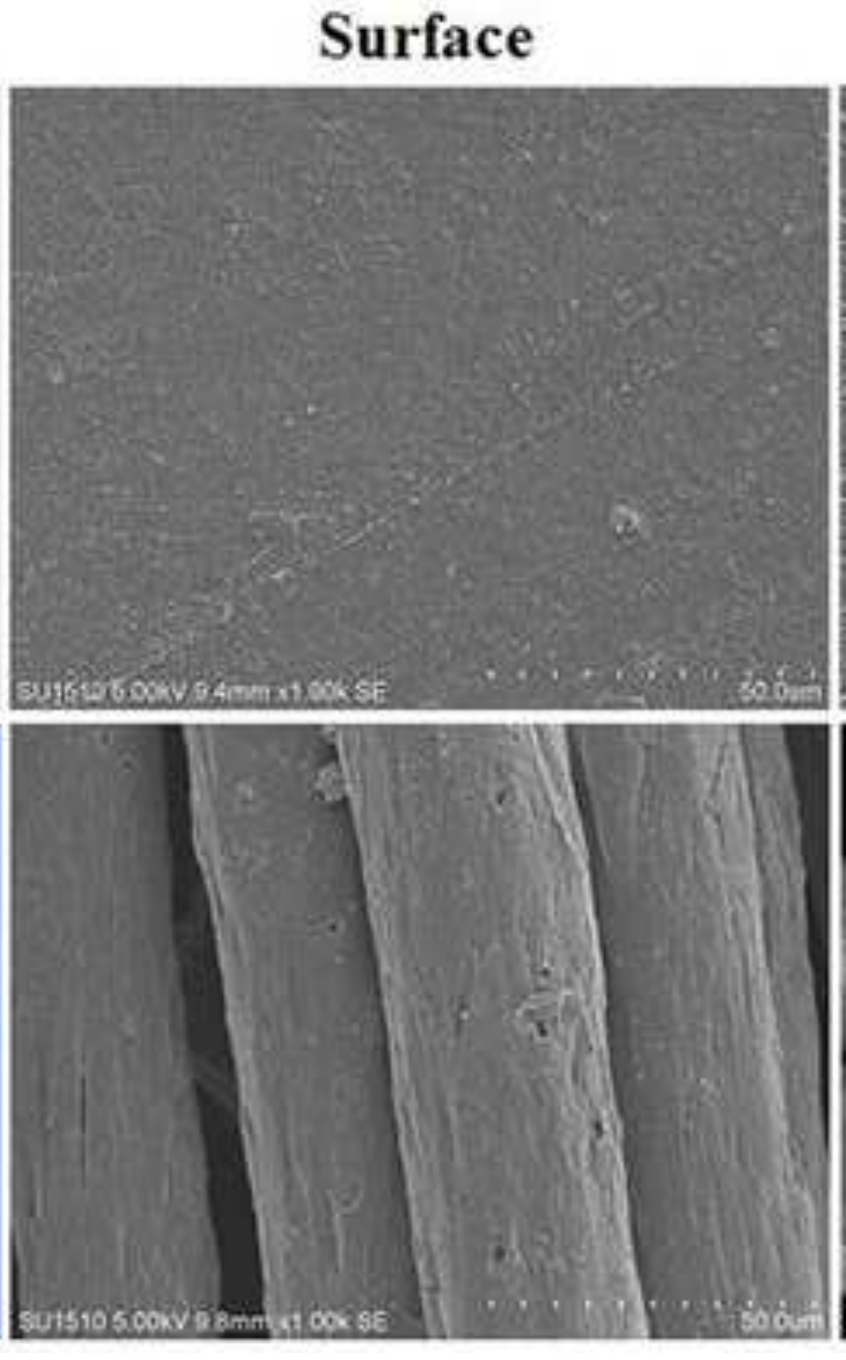

Cross Section

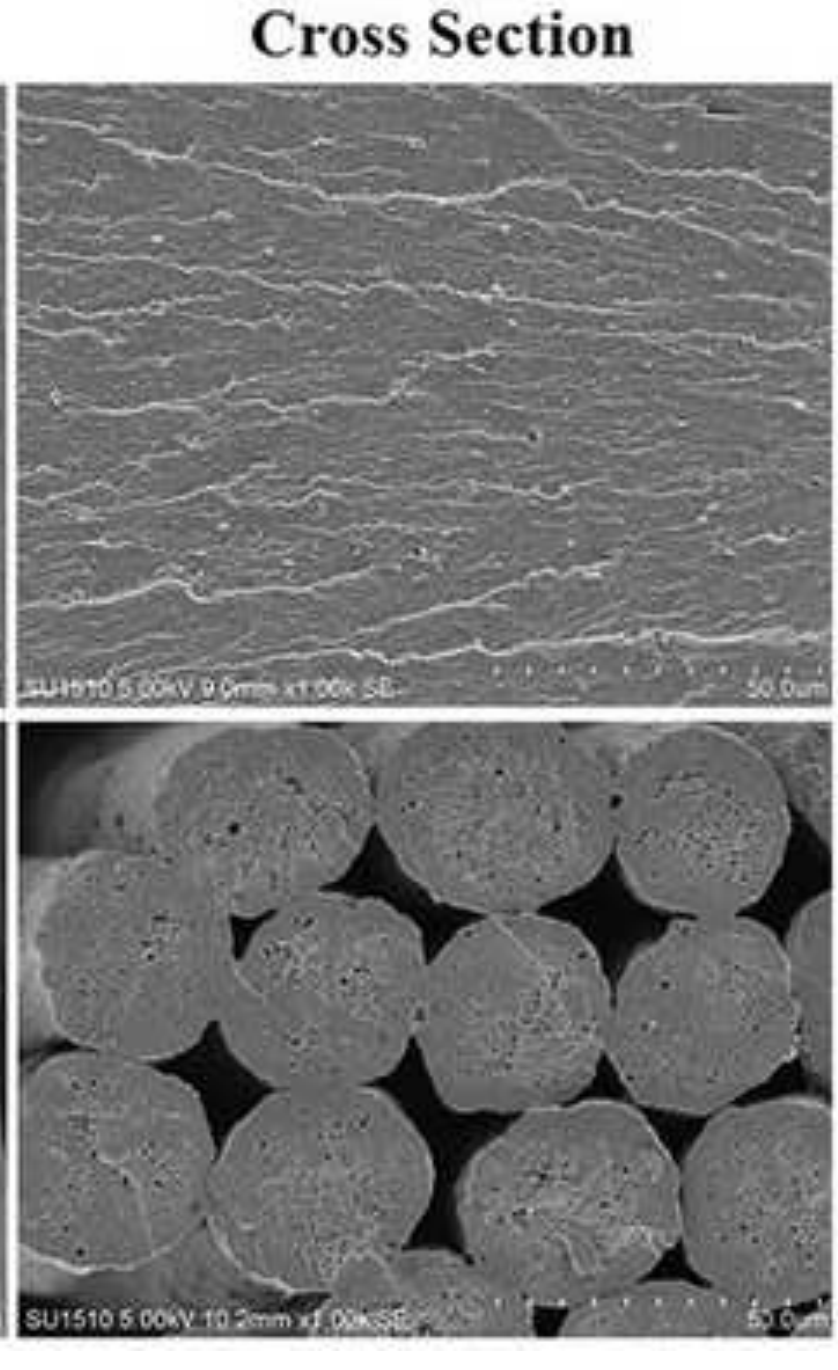

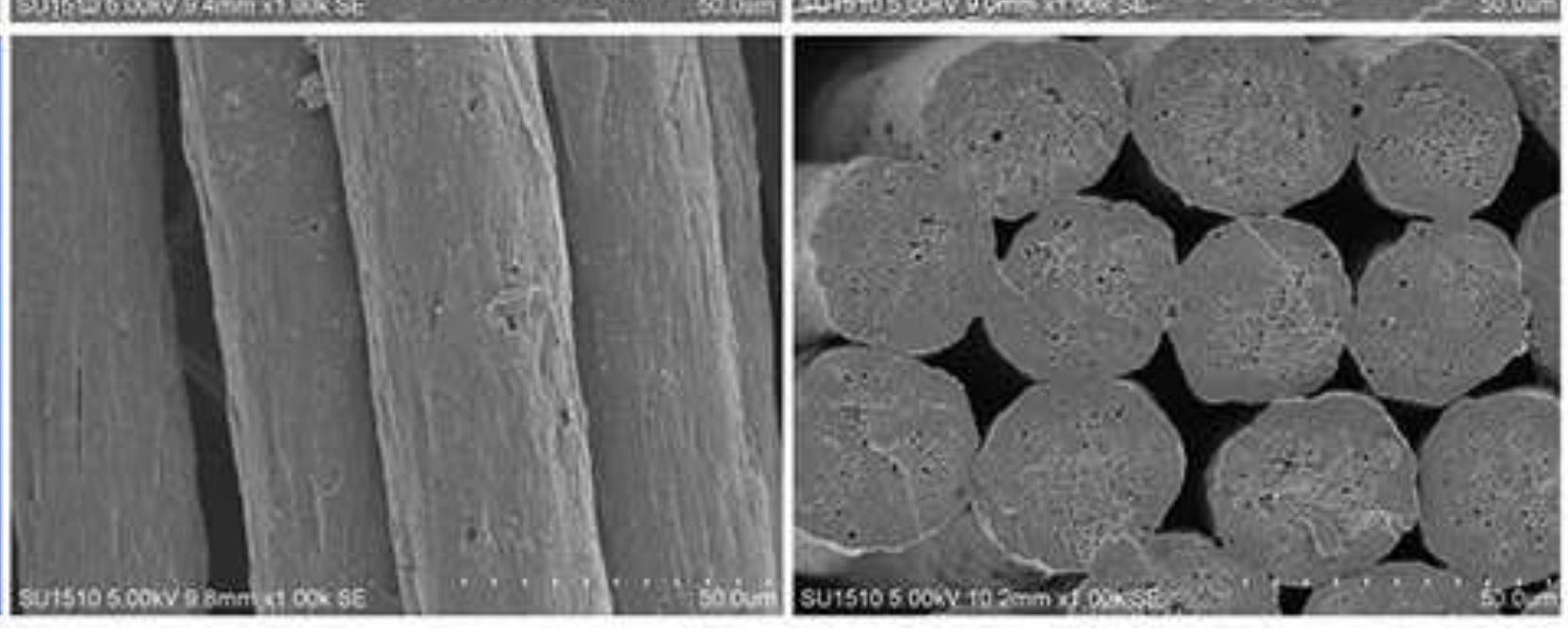



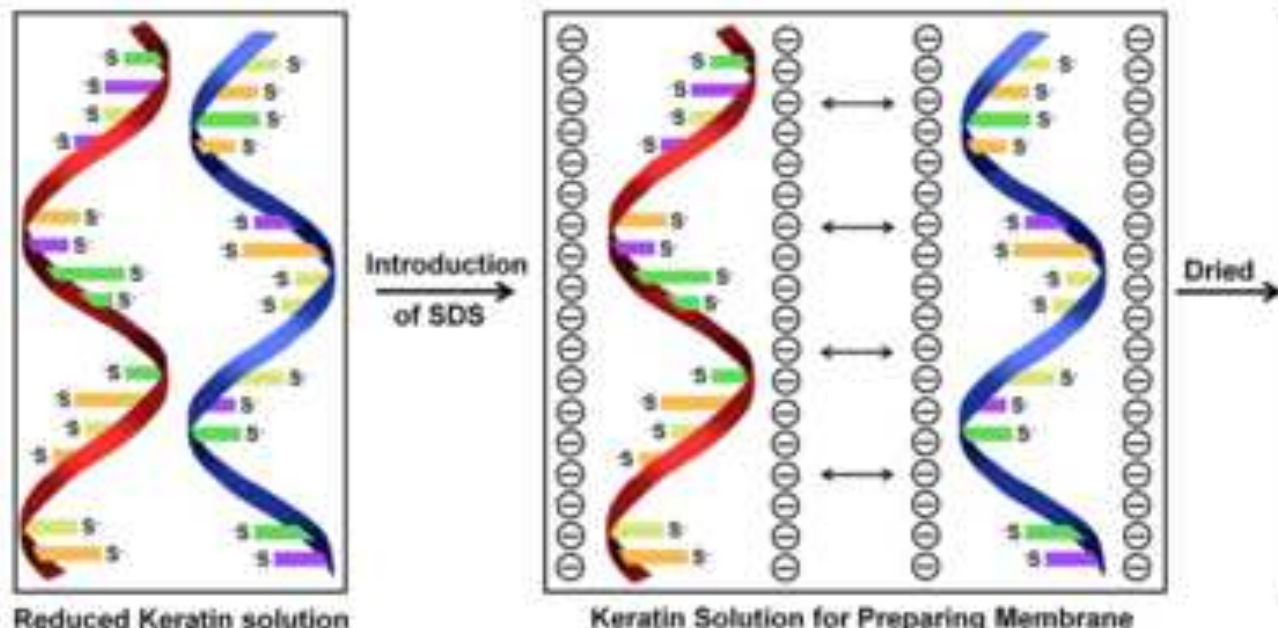

Keratin Solution for Preparing Membrane

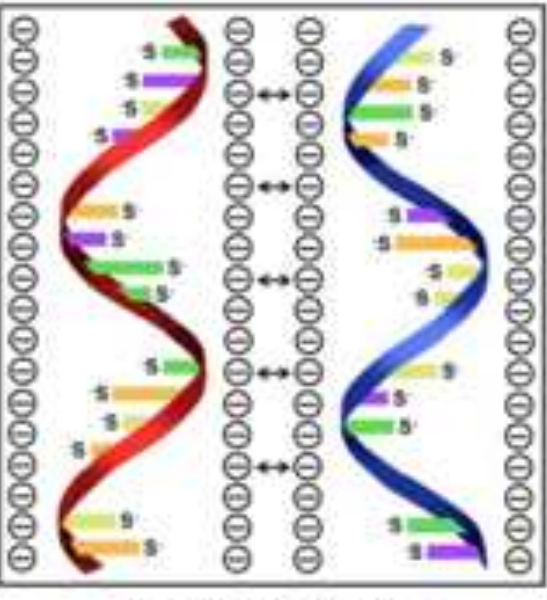

Dried Keratin Membrane

$\Theta$ The Negative Charge in Sos

$\longleftrightarrow$ Electrostatic Repulsion Between Macromolecular Chains

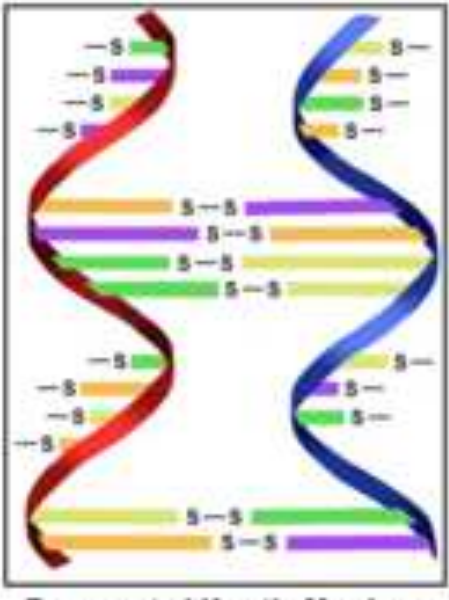

Regenerated Keratin Membrane s-s. Disulfido Bond 
Tensile Strength Break Elongation

Keratin Membrane
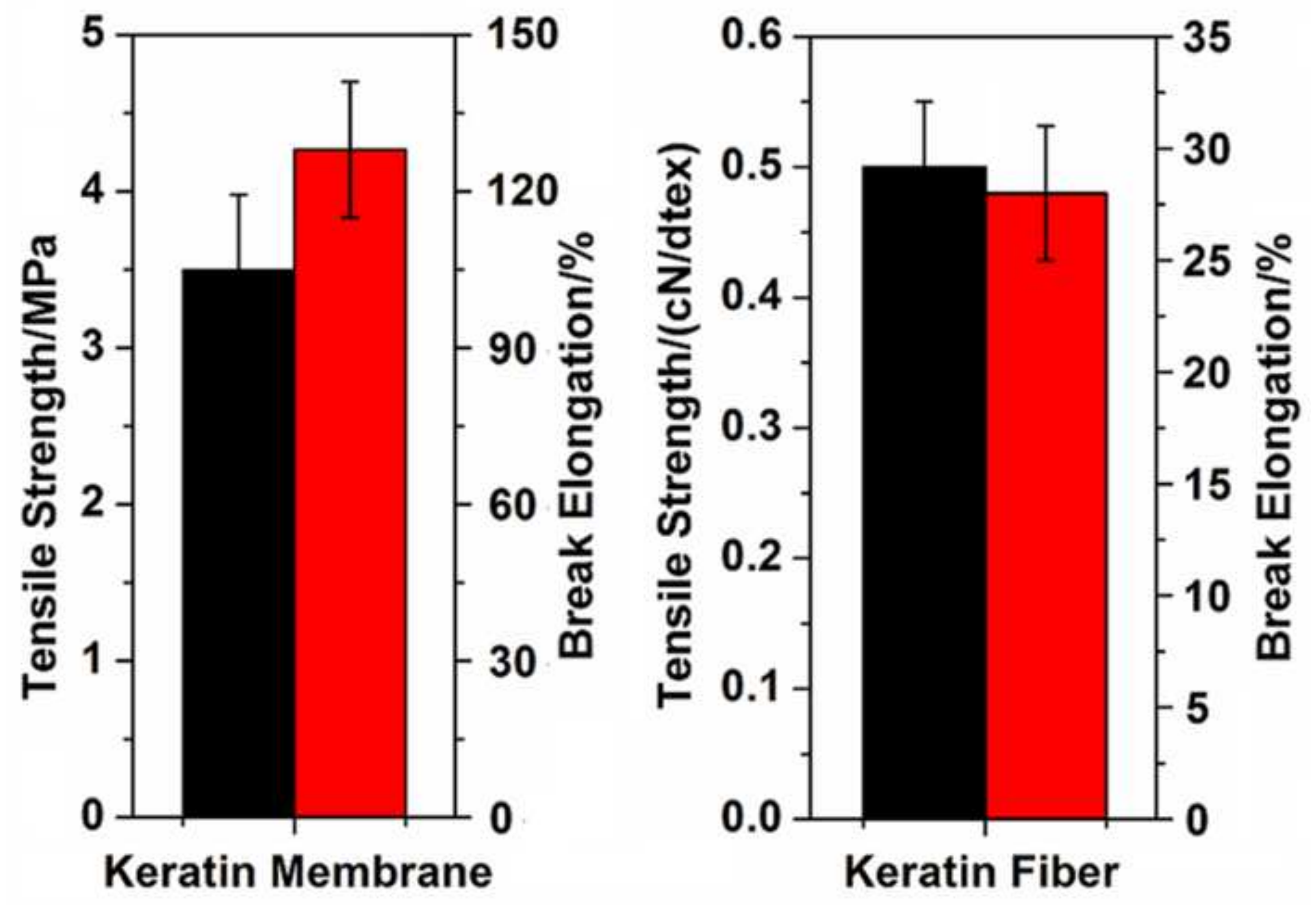


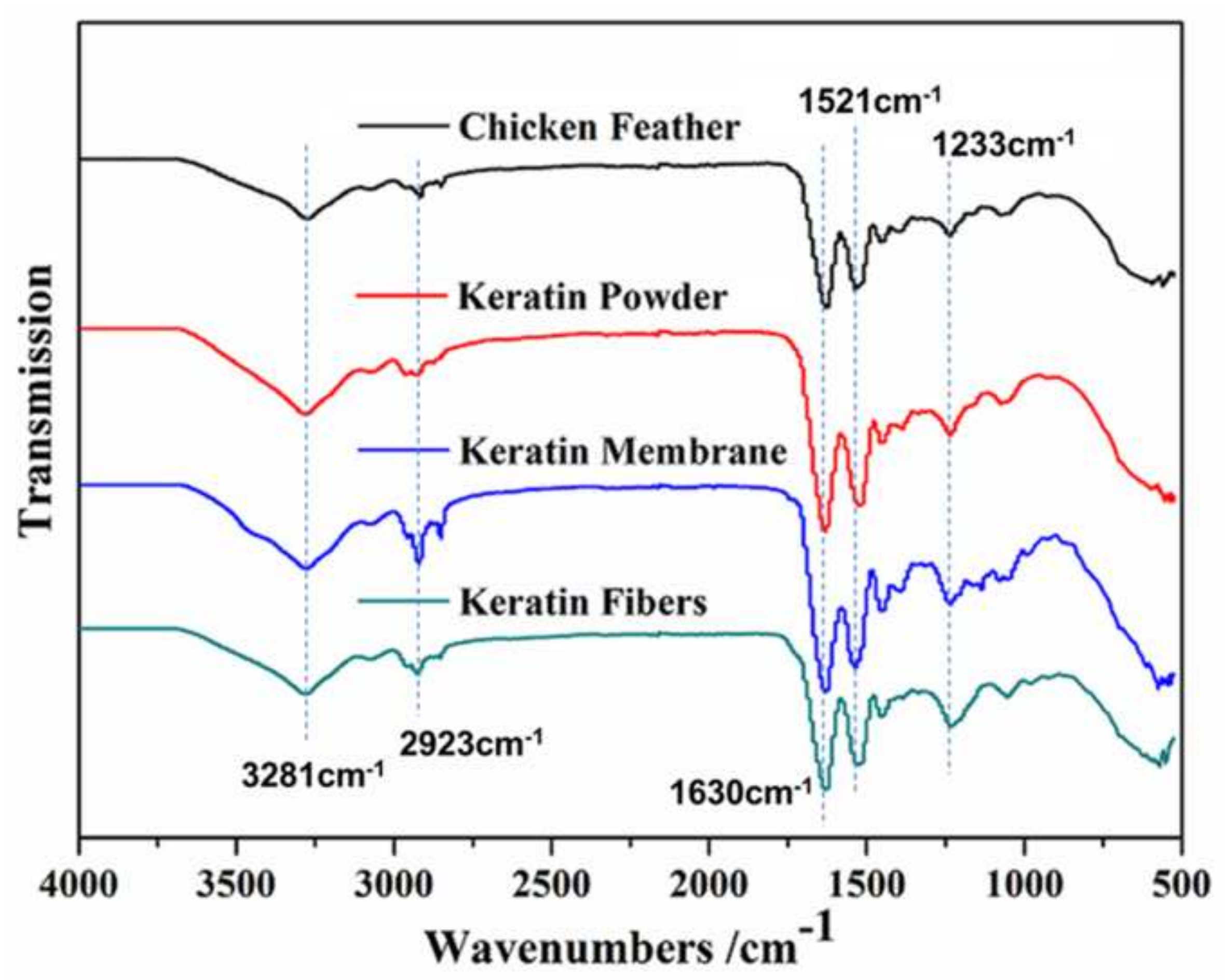


Figure 7

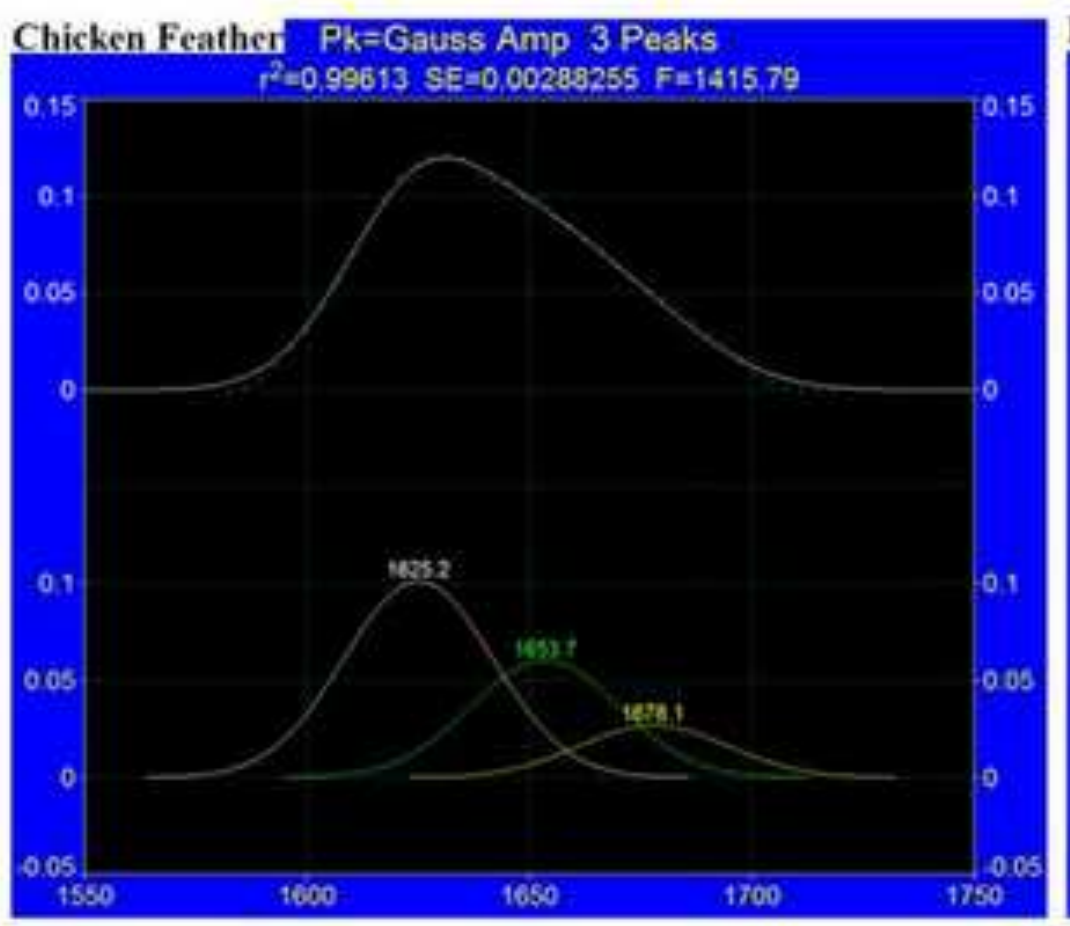

Keratin Powder PRECguss Amp 3 Peaks

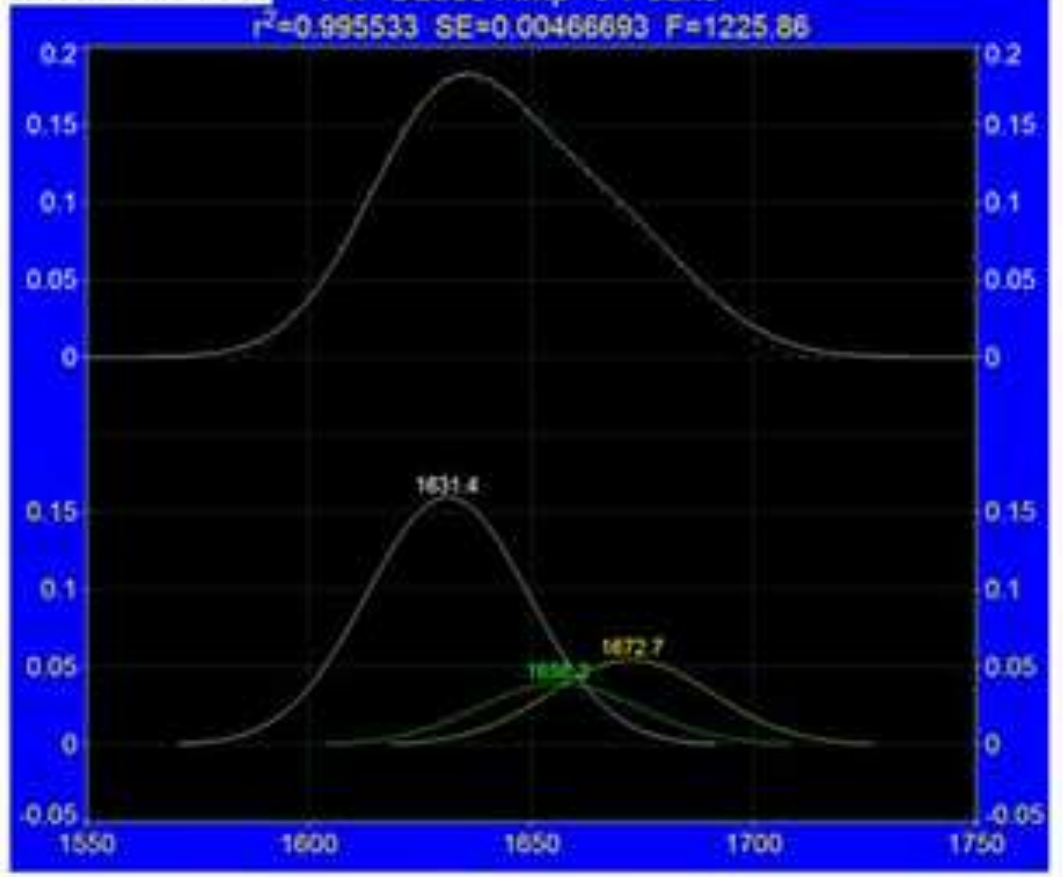

Keratin Membrane Pk=Gauss Amp 3 Peaks

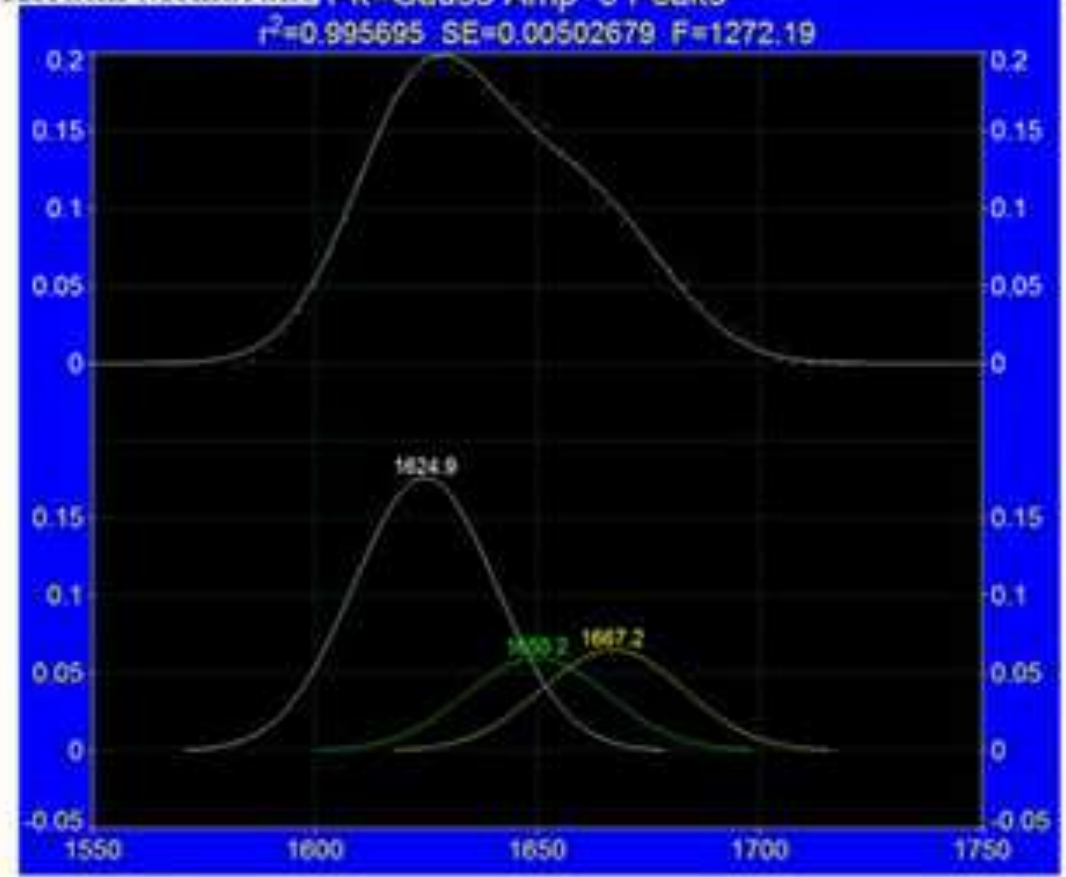

Keratin Fibers Pk=Gauss Amp 3 Peaks

$\mathrm{r}^{2}=0.99733$ SE $=0.0031016 \quad F=1805.56$

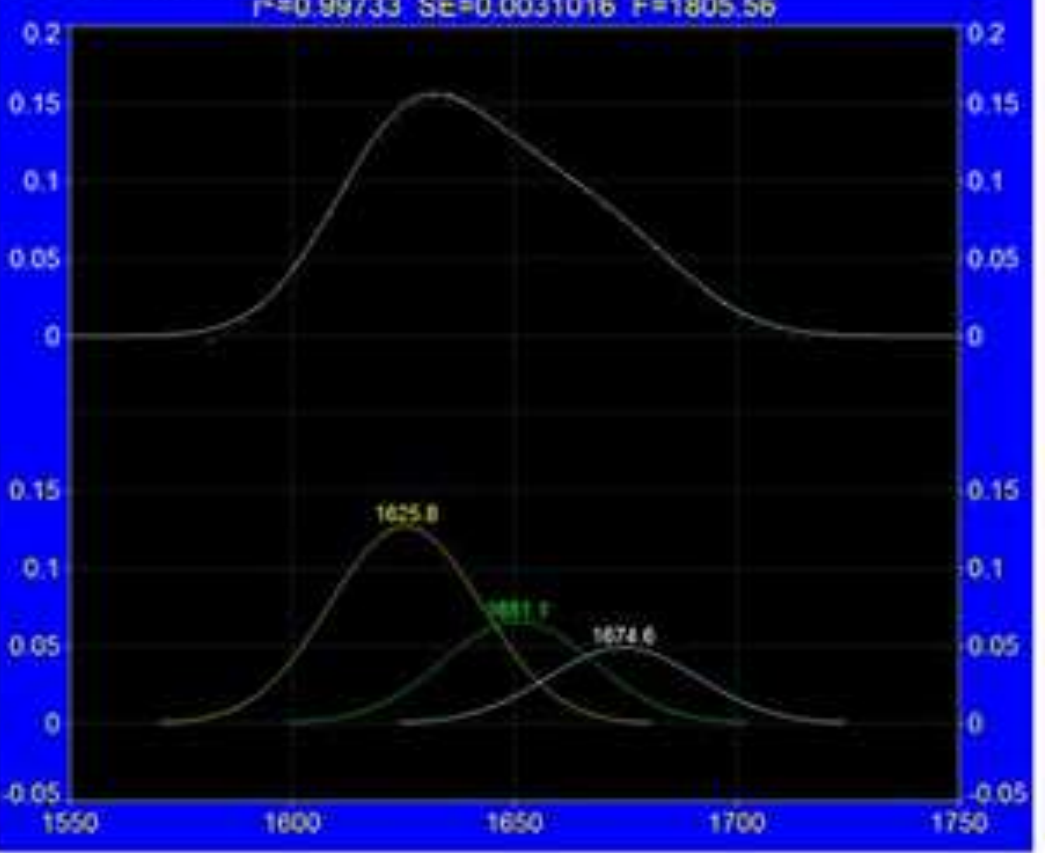



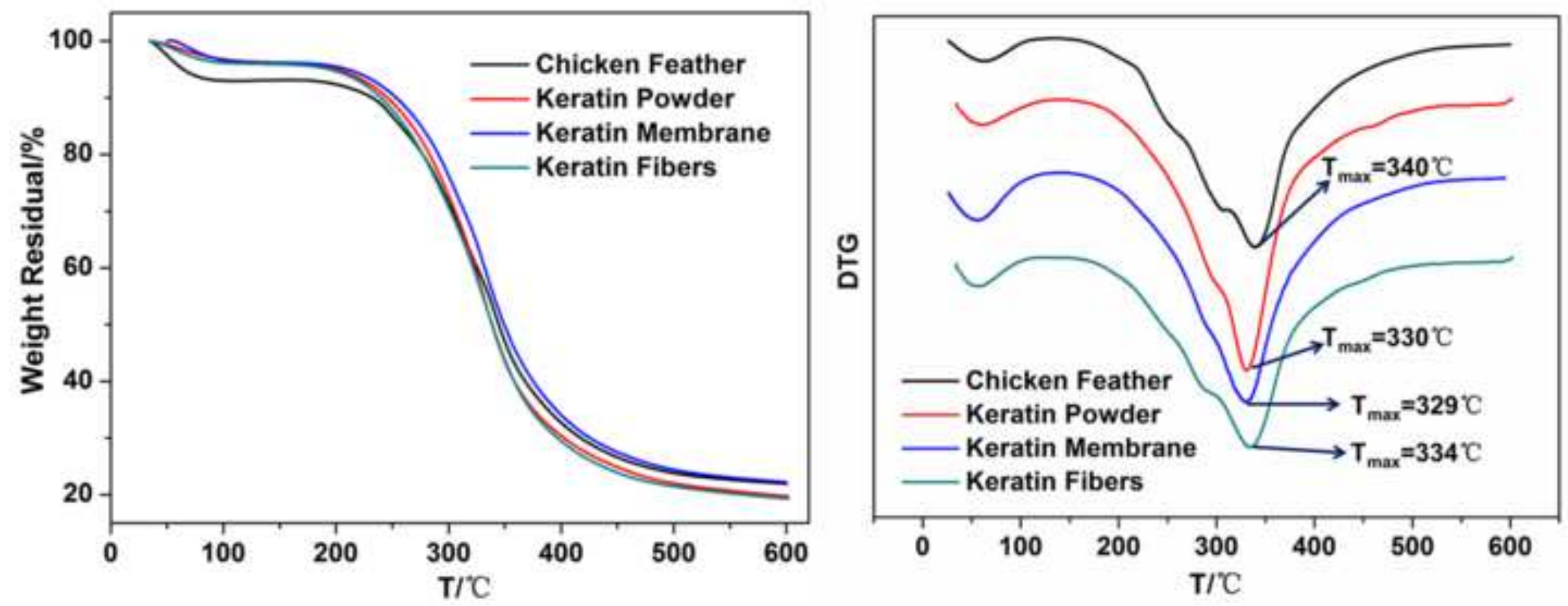

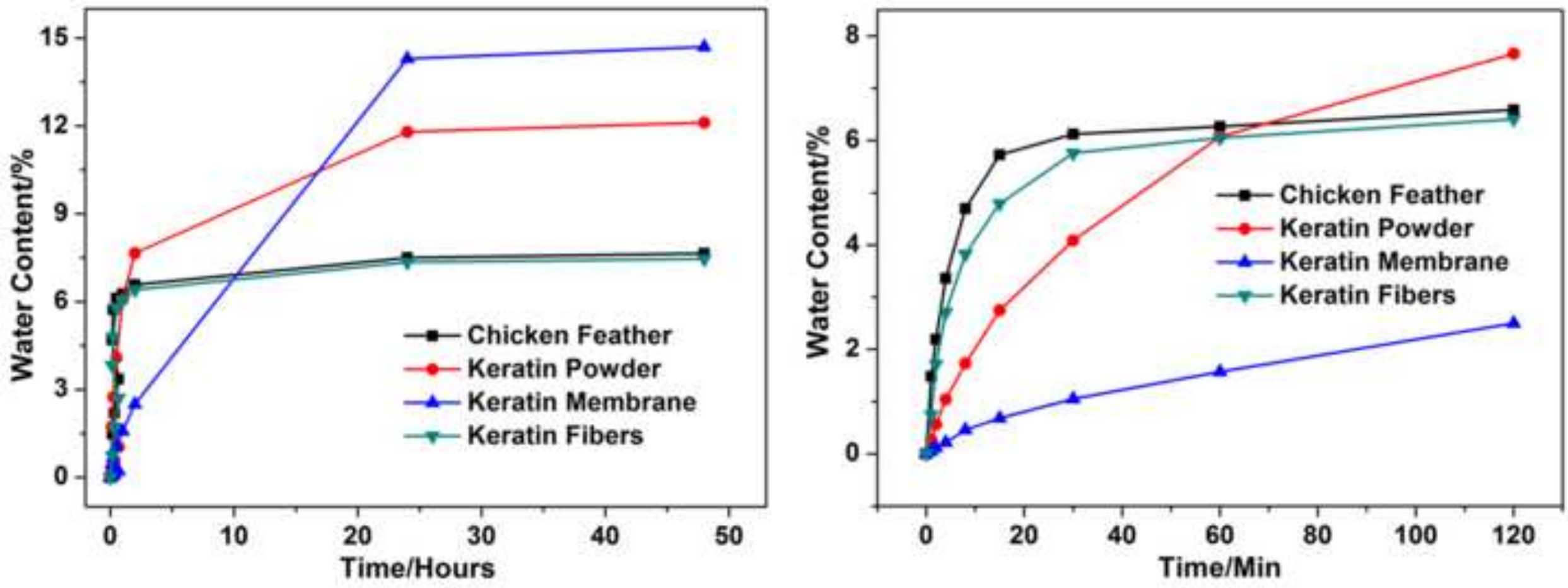


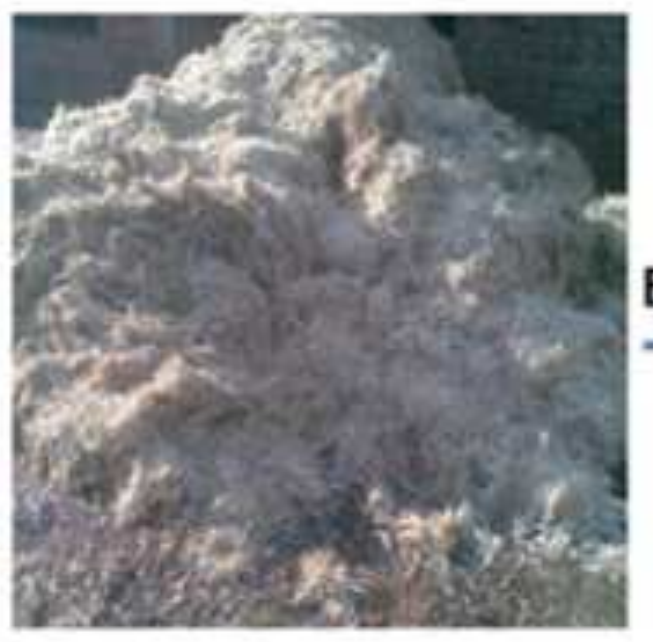

\section{Chicken Feather}

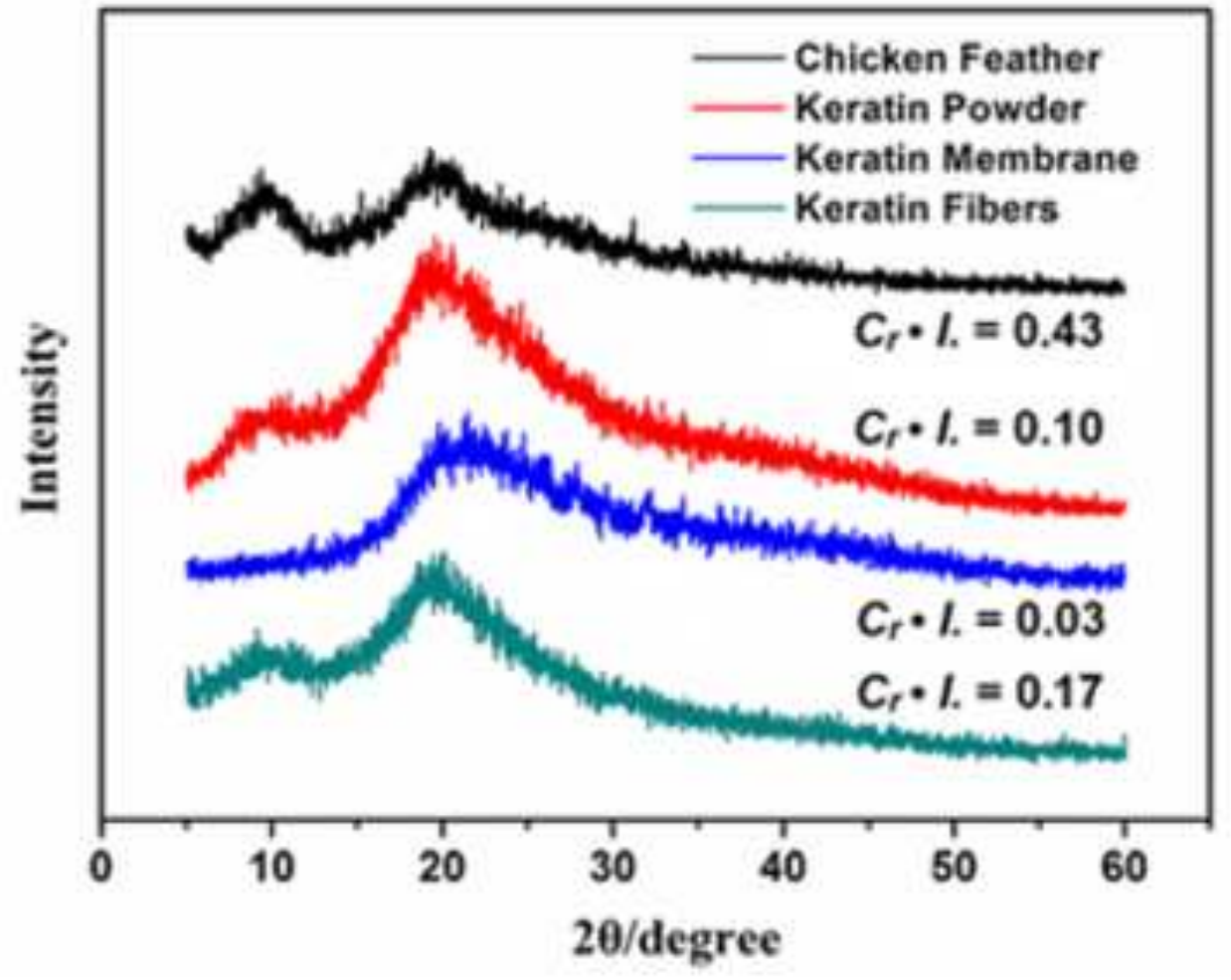

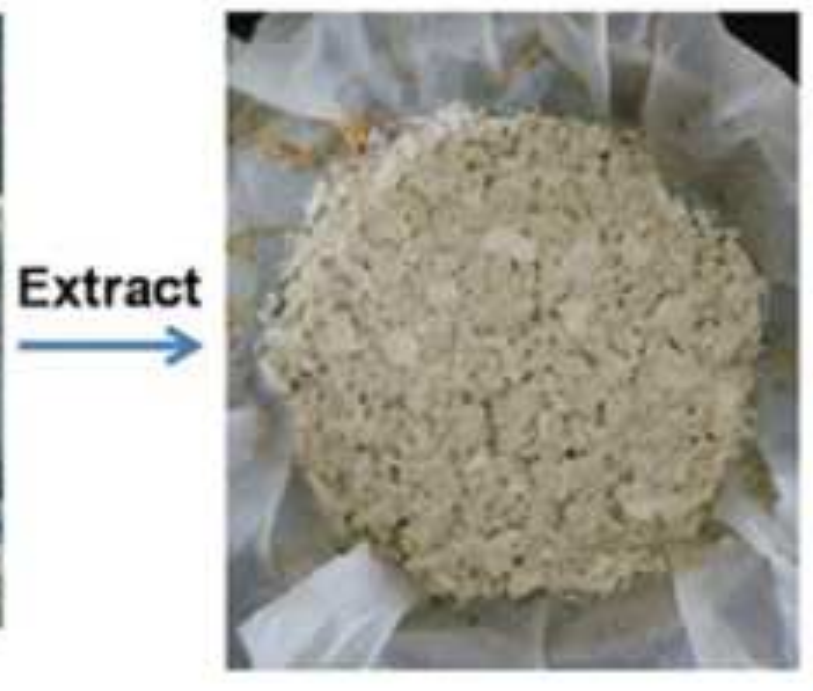
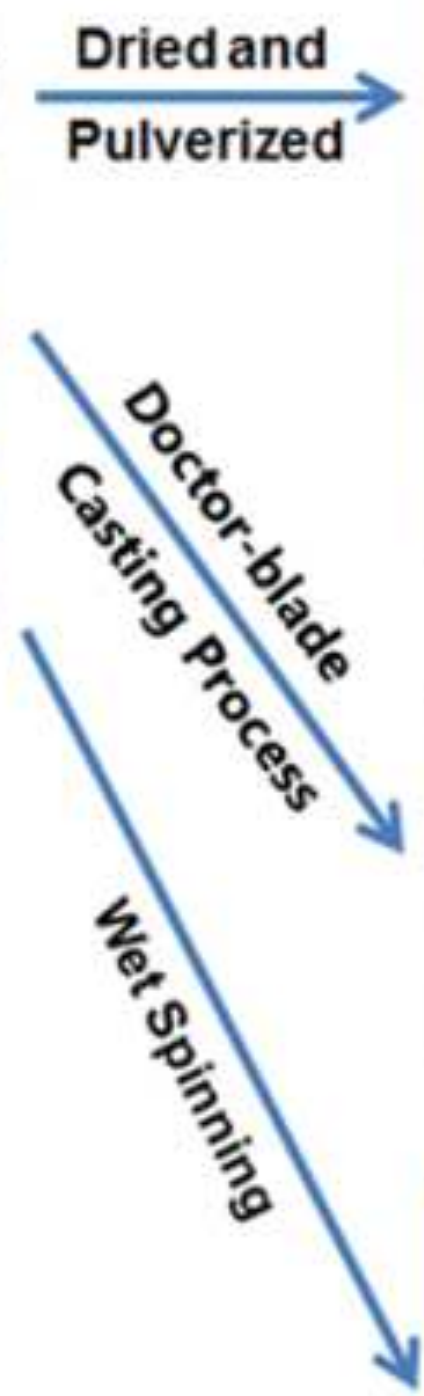

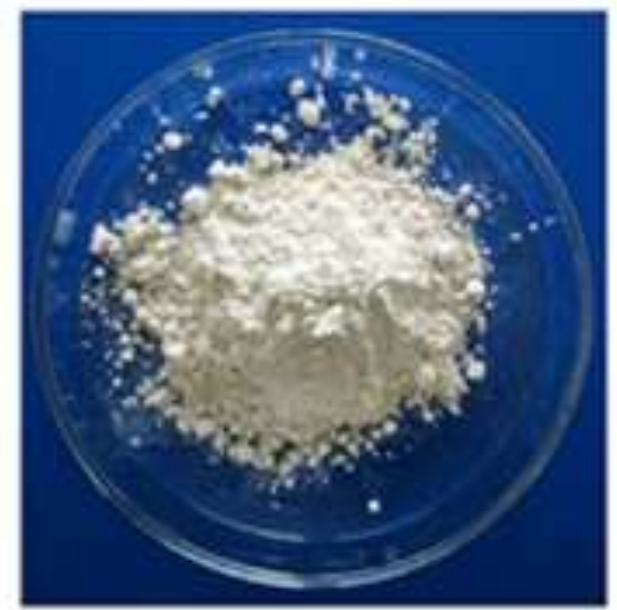

Keratin Powder

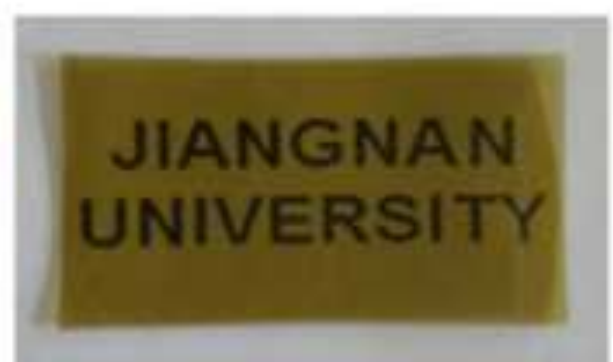

Keratin Membrane

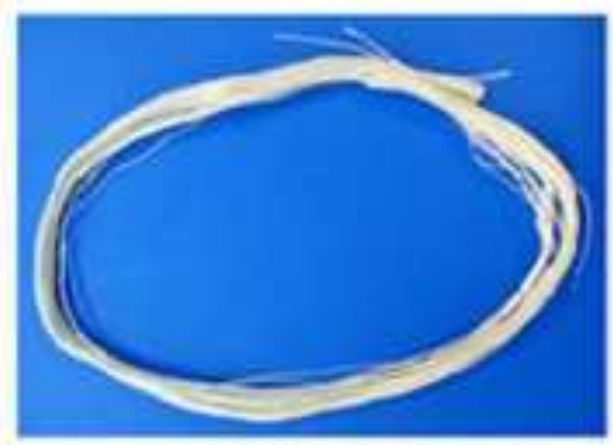

Keratin Fibers 